\title{
DECONSTRUCCIÓN Y PSICOANÁLISIS: UNA RELACIÓN DE AMISTAD
}

\author{
Maider TORNOS URZAINKI \\ Universidad de Barcelona
}

Oh, amigos míos, no hay ningún amigo.

Friedrich Nietzsche

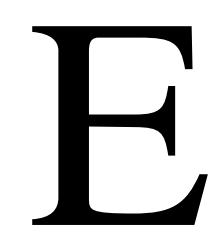

n 2001, en una entrevista con Élisabeth Roudinesco, recogida en De quoi demain, Derrida confesaba:

J'aime l'expression «ami de la psychanalyse». Elle dit la liberté d'une alliance, un engagement sans statut institutionnel. L'ami garde la réserve ou le retrait nécessaires à la critique, à la discussion, au questionnement réciproque, parfois le plus radical. [...] L'ami est celui qui approuve, acquiesce, affirme la nécessité ineffaçable de la psychanalyse, c'est-à-dire avant tout de son à-venir, mais qui s'intéresse aussi au caractère problématique, parfois artificiel, artéfactuel, donc déconstructible (Derrida y Roudinesco, 2001: 271-273).

Derrida, «amigo del psicoanálisis»: esta expresión marca la urgencia de pensar una nueva alianza crítico-política entre la deconstrucción y el psicoanálisis, en donde se dibuja la posibilidad de contemporaneizar un discurso desplazado por la centralidad de la psicoterapia y la psicología comportamental, en la sociedad farmacológica del mundo hiper-globalizado. A lo largo de los años, Derrida afirma la necesidad del psicoanálisis, pero mantiene sus reservas: el movimiento psicoanalítico del fort/da -que marca el juego incesante entre la cercanía y la distancia- queda inscrito en una relación de amistad que, a pesar de las confidencias, consigue mantener el carácter irreductible de la alteridad y su extrañeza. Obras como Spéculer-sur «Freud», Le facteur de la vérité, Freud et la scène de l'écriture, Mal d'archive, Résistances-de la psychanalyse, Pour l'amour de Lacan o États d'âme de la psychanalyse confirman que Derrida no puede pensar sin el psicoanálisis. Sin embargo, la relación de amistad nunca estará exenta de crítica, ya que «La meilleure façon d'être fidèle à un héritage, c'est de lui être infidèle, c'est-à-dire de ne pas le recevoir à la lettre, comme une totalité, mais plutôt de le prendre en défaut, d'en saisir le "moment dogmatique"» (Derrida y Roudinesco, 2001: 13). Derrida confiesa la importancia que el psicoanálisis juega en su pensamiento, pero critica la herencia recibida, porque no puede aceptar - de manera pasiva y sin cuestionar- la totalidad de ninguna ciencia. Desde una lectura deconstruccionista de amor y amistad, Derrida trata de mantener con vida el psicoanálisis y, para eso, lo exporta «dans des champs où elle n'a pas été jusqu'ici présente» (2001: 285). 
Hoy en día, según comenta Derrida (2000), el psicoanálisis está en crisis, debido a una doble resistencia que desactiva su fuerza revolucionaria: por una parte, está la resistencia del mundo frente al psicoanálisis, incapaz de aceptar ese pensamiento irreverente y poco dócil a la normativización mediático-académica; por otra parte, está la resistencia autoinmunitaria del psicoanálisis frente al mundo, que lo mantiene alejado de los dolores y sufrimientos de la vida cotidiana, como consecuencia de ese replegamiento interno sobre sí mismo. Así, al abrigo de los males y la seriedad del mundo, el psicoanálisis se convierte en un discurso arcaico, a veces incluso cómico. Aislado de la contemporaneidad del mundo, sin intención o capacidad para llegar a transformar la realidad sociopolítica del momento, el psicoanálisis atestigua la hipertrofia de una institución cerrada, dirigida exclusivamente a los psicoanalistas. En este sentido, según dice Derrida, «Tout se passe comme si, une fois assimilée ou domestiquée, la psychanalyse pouvait être oubliée. Elle deviendrait une sorte de médicament périmé au fond d'une pharmacie» (1996a: 9). A través de la deconstrucción, Derrida pretende salvar al psicoanálisis del olvido, pero sin que ello signifique construir un programa sistemático imperecedero, de validez incuestionable a pesar del paso del tiempo. Así, si Freud (19161917) define el síntoma como la irrupción -en el propio cuerpo- de un cuerpo extranjero, Derrida confiesa que el proceso de la deconstrucción es el síntoma que atraviesa la ciencia psicoanalítica: «C'est ce que je fais ici, je fais symptôme, je fais le symptôme, je suis le symptôme, c'est un rôle que je joue, sinon pour vous tous, du moins pour un certain moi de l'institution analytique» (1981: 330). Derrida -amigo (y síntoma) del psicoanálisis- ocupa una posición descentrada, sumamente crítica: primero, porque no tiene ningún título analítico (no es ni analista, ni está en formación y tampoco ha estado nunca en análisis); segundo, porque proviene de Argelia y, de acuerdo con la división geográfica que se establece en el trigésimo Congreso Anual de la API en Jerusalem (1977), Derrida es de ese the rest of the world donde todavía no ha llegado el psicoanálisis; y tercero, porque su trabajo deconstructivo lo mantiene siempre en una posición crítica, ya que según él mismo confiesa: «Je ne vois de vie que dans des lieux de dissidence» (2001: 296). El problema del psicoanálisis es que, a pesar de su fuerza clínica, se ha encerrado en la esclerosis de las instituciones, a salvo del dolor y la crueldad del mundo. Por eso, es necesario recurrir a una exterioridad extranjera, para deconstruir la entropía de una institución configurada en torno al nombre propio de su fundador y de acuerdo con una lógica de filiación transferencial. De esta manera, Derrida cuestiona el nous de la institución psicoanalítica, que se forma en torno a una ley paternal que, hasta ahora, parece incuestionable. Así, a través de la inscripción de un parricidio, Derrida sacude la autoridad del padre: ese dueño-de-la-casa, cuya plena presencia sustenta el dogmatismo amenazante de todo el sistema falo/logo-céntrico. El deseo de orfandad, entonces, es el que permite inventar una nueva comunidad -como un futuro imposible que siempre está por-venir- en la deconstrucción de los lazos fraternales de una institución excesivamente encerrada en sí misma, que actualmente es incapaz de enfrentarse con el mundo.

De este modo, Derrida apela a una política de la invención, porque «Une invention suppose toujours quelque illégalité, la rupture d'un contrat implicite, elle introduit un désordre dans la 
paisible ordonnance des choses, elle perturbe les bienséances» (1987: 11). La deconstrucción, por lo tanto, es una invención: un dispositivo de desreglamentación que abre un espacio perturbador -en constante movimiento- que impide que el psicoanálisis, fatigado y exhausto, se autoalimente de sí mismo. Así, en la deconstrucción de su endogamia institucional, el psicoanálisis - de vuelta «en» el mundo y «con» el mundo- consigue repolitizar un discurso que, una vez más, puede volver a ser sumamente crítico y provocador. Gracias a la deconstrucción, entonces, limitada no a unas formas negativas o desestructurantes, sino -paradójicamente- en tanto que posibilidad de una invención siempre renovada y por-venir, es en donde se revela «l'instauration pour l'avenir d'une possibilité ou d'un pouvoir qui restera à la disposition de tous» (1987: 16). Si bien la obra derridiana está fuertemente influenciada por el psicoanálisis - de hecho, Dosse incluso llega a preguntarse «si Derrida no tomó simplemente de Lacan ese objeto (a) que le permite construir su concepto de diferancia, como central en su obra de deconstrucción» (1992: 277)-, la intención de este trabajo es analizar las críticas que Derrida dirige contra la disciplina psicoanalítica, con el fin de repolitizar su pensamiento. Desde la teoría deconstruccionista del signo lingüístico, Derrida cuestiona la lógica falo/logo-céntrica que determina el alcance del psicoanálisis y demuestra que la cura psicoanalítica no debe ser entendida como un proceso teleológico, sino como un proceso interminable. A partir de la infinitización del proceso de la cura, Derrida intenta actualizar el psicoanálisis, para que pueda volver a pensar el dolor y la crueldad del mundo contemporáneo. Sin embargo, Derrida puntualiza: «Malgré les apparences, la déconstruction du logocentrisme n'est pas une psychanalyse de la philosophie» (1967b: 293).

\section{La desestructuración del motivo lítico y el análisis interminable}

A rose is a rose is a rose is a rose. Gertrude Stein

Según explica Derrida (1996a), hay dos motivos constitutivos del concepto de análisis (analuein): por una parte, está el motivo arqueológico o anagógico, que indica una vuelta recurrente al origen; por otra parte, un motivo lítico o litológico, que marca la descomposición, la destrucción, la ruptura o la disolución. De esta manera, el análisis implica un double bind: es fruto de una tensión o conflicto de fuerzas entre una demanda arqueológica, que remite a una hermenéutica del sentido, y una demanda lítica, que marca su propia descomposición. Así, el análisis -en referencia siempre a la solución, el desvelamiento o la explicación de un problema oculto- es una «tâche pénélopeenne ou contre-penélopéenne», que se hace y se deshace sin descanso (Derrida, 1996a: 25). No obstante, según explica Derrida (1996a), el psicoanálisis tiende a alejar la autodescomposición inherente del movimiento lítico (fort), con el fin de alcanzar el origen arqueológico ( $d a$ ), en donde se esconde el secreto inconfesable que -al parecer- ocasionó el síntoma. Así, dice Derrida, el psicoanálisis

C'est brûler d'une passion. C'est n'avoir de cesse, interminablement, de chercher l'archive là où elle se dérobe. C'est courir après elle là où, même s'il y en a trop, quelque chose en elle s'anarchive. C'est se porter vers elle d'un désir compulsif, répétitif et nostalgique, un désir irrépressible de retour à l'origine, un mal du pays, une nostalgie du retour au lieu le plus archaïque du commencement absolu (1995: 142). 
El motivo arqueológico remite al origen (arkhé): lugar de la autoridad, donde se forja la ley económica que sirve a la conservación y la domiciliación (ô̂kos) de la memoria. Sin embargo, desde el silencio de una repetición creadora, la pulsión de muerte trabaja contra el proceso arqueológico del análisis, convirtiéndose en el mal que excede el análisis y descompone el archivo. En este sentido, comenta Derrida,

[la pulsion de mort; la pulsion d'agression; la pulsion de destruction] est au travail, mais dès lors qu'elle opère toujours en silence, elle ne laisse jamais d'archive qui lui soit propre. Sa propre archive, elle la détruit d'avance, comme si c'était là en vérité la motivation même de son mouvement le plus propre. Elle travaille à détruire l'archive: à la condition d'effacer mais aussi en vue d'effacer ses «propres» traces qui ne peuvent dès lors être proprement dites «propres» (1995: 24).

Para Derrida, la resistencia hiperbólica que provoca el mal en el archivo y en el análisis es la compulsión demoníaca de repetición o la pulsión de muerte: ese carácter analítico, pero a la vez disociativo y desligado que recoge los fenómenos de la anomalía, lo accidental, lo marginal o lo parasitario y que se convierte en el riesgo que perturba el análisis, obligándole a reproducir maquinalmente «chaque fois "plus mort" et "plus fort", le processus de son déclenchement» (1972a: 354). Por eso, si Derrida convierte el motivo lítico, que deshace y descompone la metafísica de la propiedad, en la herramienta primordial de la deconstrucción, es evidente que su relación con el psicoanálisis tiene, como él mismo confiesa (1996a), un marcado (re)gusto a muerte, que llega incluso a condicionar sus encuentros y conversaciones con Lacan, la primera de ellas en 1966, en Baltimore: la ciudad de la muerte ${ }^{1}$. A través de la compulsión de repetición o la pulsión de muerte, Derrida deconstruye la pasión que el psicoanálisis - como ciencia del archivo- tiene por el origen (arkhé): ese deseo, siempre doloroso, que surge por la necesidad infatigable (también imposible) de reconquistar el espacio onfálico, donde descansa el secreto y la verdad del análisis. "Acepta mi solución», le decía Freud a Irma, «si todavía tienes dolores, es exclusivamente por tu culpa ${ }^{2} »$ (Freud,

\footnotetext{
${ }^{1}$ Cuenta Derrida: «Quand j'ai rencontré Lacan à Baltimore pour la première fois, en 1966, et quand nous fûmes présentés l'un à l'autre par René Girard, son premier mot fut, dans un soupir amical: "Il fallait donc attendre d'arriver ici, et à l'étranger, pour se rencontrer!" Et je remarque ici peut-être à cause du problème de la destinerrance qui nous attend et peut-être à cause du nom de mort de Baltimore (Baltimore, danse ou transe et terreur), Baltimore qui est aussi la ville de Poe dont $\mathrm{j}$ 'avais en vain cherché la tombe ces jours-là mais en tout cas pu visiter la maison en cette occasion (je suis allé chez Poe en 1966), je remarque ici peut-être à cause du nom de mort de Baltimore que les deux seules fois où nous sommes rencontrés et où nous avons un peu parlé l'un avec l'autre, il fut question de mort entre nous et d'abord dans la bouche de Lacan. À Baltimore, par exemple, il me parla de la façon dont il pensait qu'il serait lu, en particulier par moi, après sa mort» (1996a: 69).

${ }_{2}^{2}$ Años después, en el ensayo Análisis terminable e interminable (1937), Freud manifiesta sus dudas con respecto al carácter teleológico del análisis. Así, dice Freud, «Primero hay que ponerse de acuerdo sobre lo que se mienta con el multívoco giro «final o término de un análisis». En la práctica es fácil decirlo. El análisis ha terminado cuando analista y paciente ya no se encuentran en la sesión de trabajo analítico. Y esto ocurrirá cuando estén aproximadamente cumplidas dos condiciones: la primera, que el paciente ya no padezca a causa de sus síntomas y haya superado sus angustias así como sus inhibiciones, y la segunda, que el analista juzgue haber hecho consciente en el enfermo tanto de lo reprimido, esclarecido tanto de lo incomprensible, eliminado tanto de la resistencia interior, que ya no quepa temer que se repitan los procesos patológicos en cuestión. Y si se está impedido de alcanzar esta meta por dificultades externas, mejor se hablará de un análisis imperfecto [unvollstdndig] que de uno no terminado [unvollendet]» (1937: 222). Y Freud continúa: «[En 1927 Ferenczi dice que] ...el análisis no es un proceso sin término, sino que puede ser llevado a un cierre natural si el analista tiene la pericia y paciencia debidas». Opino que ese trabajo equivale más bien a una advertencia de no poner como meta del análisis su abreviación, sino su profundización. Ferenczi añade todavía la valiosa puntualización
} 
1900: 174). En cambio, frente a esta afirmación freudiana, Derrida opina que hay un exceso que desarticula el análisis y el orden del sentido en el que éste se sustenta, impidiendo la solución definitiva del problema, al que sí parece llegar Freud en el caso de La inyección de Irma. Para Derrida (1996a), hay un restanalyse o restance, que no es una frontera exterior -ajena al psicoanálisis-, sino un exceso de sentido que extiende el propio proceso del análisis al infinito. Así, frente a la nostalgia psicoanalítica por el origen y la fe en la solución del problema, la deconstrucción es el drama de un análisis interminable, que pone en cuestión

non seulement la possibilité mais le désir ou le fantasme d'une ressaisie de l'originaire, le désir ou le fantasme aussi de rejoindre jamais le simple, quel qu'il soit. Il s'agit là d'un mouvement non seulement contre-archéologique mais contre-généalogique de la déconstruction (1996a: 42).

Para Derrida, todo comienza con una citación y el origen, más que un momento inaugural, es una ficción múltiple: «Singulier pluriel qu'aucune origine singulière n'aura jamais précédé. Germination, dissémination. Il n'y a pas de première insémination. La semence est d'abord essaimée. L’insémination “première” est dissémination. Trace, greffe dont on perd la trace» (1972a: 369). Ahora, la intención de Derrida es deconstruir la autoridad del sentido: la finalidad teleológica de la

de que es igualmente decisivo para el éxito que el analista haya aprendido bastante de sus propios «yerros y errores», y cobrado imperio sobre los «puntos débiles de su propia personalidad» (248). Y sigue Freud más adelante: «Es indiscutible que los psicoanalistas no han alcanzado por entero en su propia personalidad la medida de normalidad psíquica en que pretenden educar a sus pacientes. Opositores del análisis suelen señalar en son de burla ese hecho y emplearlo como argumento para demostrar la inutilidad del empeño analítico. Uno podría rechazar esta crítica como reclamo ilegítimo. Los analistas son personas que han aprendido a ejercer un arte determinado y, junto a ello, tienen derecho a ser hombres como los demás. [...] el analista, a consecuencia de las particulares condiciones del trabajo analítico, será efectivamente estorbado por sus propios defectos para asir de manera correcta las constelaciones del paciente y reaccionar ante ellas con arreglo a fines. Por tanto, tiene su buen sentido que al analista se le exija, como parte de su prueba de aptitud, una medida más alta de normalidad y de corrección anímicas; y a esto se suma que necesita de alguna superioridad para servir al paciente como modelo en ciertas situaciones analíticas, y como maestro en otras. Por último, no se olvide que el vínculo analítico se funda en el amor por la verdad, es decir, en el reconocimiento de la realidad objetiva, y excluye toda ilusión y todo engaño» (249). Y, hacia el final, comenta: «Todo analista debería hacerse de nuevo objeto de análisis periódicamente, quizá cada cinco años, sin avergonzarse por dar ese paso. Ello significaría, entonces, que el análisis propio también, y no sólo el análisis terapéutico de enfermos, se convertiría de una tarea terminable \{finita\} en una interminable \{infinita\}» (251). Finalmente, concluye: «No tengo el propósito de aseverar que el análisis como tal sea un trabajo sin conclusión. Comoquiera que uno se formule esta cuestión en la teoría, la terminación de un análisis es, opino yo, un asunto práctico. Todo analista experimentado podrá recordar una serie de casos en que se despidió del paciente para siempre «rebus bene gestis». Mucho menos se distancia la práctica de la teoría en casos del llamado «análisis del carácter». Aquí no se podrá prever fácilmente un término natural, por más que uno evite expectativas exageradas y no pida del análisis unas tareas extremas. Uno no se propondrá como meta limitar todas las peculiaridades humanas en favor de una normalidad esquemática, ni demandará que los «analizados a fondo» no registren pasiones ni puedan desarrollar conflictos internos de ninguna índole. El análisis debe crear las condiciones psicológicas más favorables para las funciones del yo» (251).

A partir de aquí, Deleuze y Guattari se preguntan: «El problema singularmente práctico y concreto es: ¿esta historia tiene un fin? ¿podemos acabar con un análisis, puede terminarse el proceso de la cura, sí o no? ¿puede concluirse o está condenado a una continuación hasta el infinito? [...] Una enorme belleza anima este texto de Freud [(1937)]: al mismo tiempo que algo desesperado, desencantado, cansado, hay una serenidad [...] Es el testamento de Freud. Va a morir y lo sabe. Sabe que algo no funciona en el psicoanálisis: ¡la cura tiende cada vez más a ser interminable!» (1972: 71). Y continúan: «Pues, ¿qué significa "era, pues, aquello lo que esto quería decir”? Aplastamiento del "pues” sobre Edipo y la castración. Suspiro de alivio: ves, el coronel, el instructor, el educador, el patrón, todo esto quería decir aquello, Edipo y la castración, “toda la historia en una nueva versión"... No decimos que Edipo y la castración no sean nada: se nos edipiza, se nos castra» (73). Finalmente, terminan con las siguientes palabras: «el mal de cualquier modo está hecho, la cura eligió el camino de la edipización, todo alfombrado de residuos, contra la esquizofrenización que debe curarnos de la cura» (74). 
metafísica occidental, en donde descansa la verdad del discurso. Frente a la concepción hegeliana de la historia, como historia del desvelamiento progresivo del sentido, Derrida -influenciado por la crítica de Althusser (1965) al concepto hegeliano de «historia»- propone una multiplicidad diseminante de historias desplazadas y ritmos diferentes. De este modo, destruyendo esa linealidad teleológica (y, por qué no decirlo, tautológica), Derrida arremete contra la historia del sentido en la que se apoya todo el sistema falo/logo-céntrico, diseminando la unidad de un sentido omniabarcador y autocomplaciente. Al final, dice Derrida (1972b), hay que arriesgarse «a no-querer-decir-nada»; hay que dejar que la palabra guarde el silencio, en un gesto marcadamente político, que no supone incurrir en un vacío apático, sino que apela a la necesidad de un juego perverso que deconstruye -al infinito- la lógica del sentido en la que se sustenta el discurso hegemónico. De esta manera, Derrida destruye la confianza que el psicoanálisis deposita en el logos y la palabra plena heideggeriana como verdad de adecuación u homoiôsis - y cuestiona el carácter teleológico del proceso analítico.

En Le Séminaire sur «La Lettre volée», a través de un cuento de Edgar Allan Poe, Lacan intenta descubrir cómo funciona la cadena significante. A partir del juego de la carta robada $-\mathrm{y}$ de acuerdo con las enseñanzas de Heidegger-, Lacan llega a la conclusión de que «c'est à ce qu'elle [la lettre] se cache, qu'elle s'offre à eux le plus vraiment» (1955-1956: 21). Según dice Lacan, la carta robada se desplaza y, en ese movimiento reiterativo que hace avanzar la ficción, desvela la verdad de un significante que - paradójicamente- se descubre cuanto más se oculta y se esconde. Sin embargo, para Lacan, si bien la carta pasa y circula sin descanso, nunca soporta la partición: «si c'est d'abord sur la matérialité du signifiant que nous avons insisté, cette matérialité est singulière en bien des points dont le premier est de ne point supporter la partition. Mettez une lettre en petits morceaux, elle reste la lettre qu'elle est» (1955-1956: 24). La materialidad del significante lacaniano apela a la indivisibilidad de una carta que, a través de su desplazamiento compulsivo y mortífero, condiciona la posición de los protagonistas del cuento que la detentan por un tiempo ${ }^{3}$. El significante lacaniano, por lo tanto, no soporta la partición: no es un objeto parcial o divisible ${ }^{4}$-que pueda sumarse a la cadena de los objetos sustitutivos-, sino que ocupa una posición trascendental, que designa el conjunto de los efectos de significado, organizando el juego de reenvíos de la estructura simbólica. De esta manera, el juego lacaniano de la carta robada anuncia la preeminencia del orden simbólico sobre el sujeto, que queda a merced de la trayectoria de un significante que «manque à sa place»-a diferencia de la dimensión de lo real, «qu'il est toujours et en tout cas, à sa place» (1955-1956: 25)-, haciendo de la castración simbólica el significante trascendental donde descansa la verdad del discurso. Así, Lacan moviliza -hasta cierto punto- la función del significante, ya que es su desplazabilidad la que determina el comportamiento de los protagonistas del cuento, que quedan sujetos al juego que provoca esa carta robada, que siempre falta en su lugar. No obstante, para Lacan, el hecho de que el significante pueda trasladarse y cambiar de sitio no significa que no tenga un lugar

\footnotetext{
${ }^{3}$ Las palabras exactas de Lacan son: «le déplacement du signifiant détermine les sujets dans leurs actes [...] c'est la lettre et son détour qui régit leurs entrées et leurs rôles» (1955-1956: 30).

${ }^{4}$ Según explica Derrida, en "Le Facteur de la Vérité" (1975), una de las estrategias del feminismo ha consistido en reducir el falo lacaniano al papel de un objeto parcial, destruyendo su posición trascendental.
} 
propio y originario al que regresar: al fin y al cabo, dice Lacan, "puisqu' elle [la lettre] peut subir un détour, c'est qu'elle a un trajet qui lui est propre" (1955-1956: 29). Y ese trayecto, según explica Lacan, remite a la falta y el vacío - como sentido propio de la carta-, ya que si bien el significante falta en su lugar, lo que nunca falta es la condición misma de la 'falta', porque el destino de la carta robada es la marca de la castración simbólica que imprime el lenguaje. Por eso, la carta lacaniana no sólo elude la partición, sino que en cierto sentido también escapa a la movilidad -por mucho que Lacan insista en ello-, ya que no puede desprenderse de la dimensión de la falta que introduce la ley de la castración simbólica, impuesta por el Nombre-del-Padre. Así, para Lacan, la verdad del discurso radica en conseguir que la carta llegue a su destino -en un movimiento circular obsesivo, que regresa a su lugar de origen-, en donde la carta encuentra su sentido propio, que coincide con el corte que introduce la ley de la castración simbólica del lenguaje. Entonces, de acuerdo con la teoría lacaniana, el significante fálico - esa función trascendental que gobierna la estructura simbólica y el juego de la significación - se convierte en la verdad del discurso, que obliga a realizar un trabajo hermenéutico, como desvelamiento progresivo del material semántico que queda entrelazado con el registro de la ficción. Sin embargo, según explica Major (2001), el juego deconstruccionista propuesto por Derrida produce una brecha en el orden simbólico y transforma la estructura triangular del cuento en una estructura cuadrangular, al habilitar de nuevo el orden imaginario que posibilita el desdoblamiento de la carta ${ }^{5}$. De este modo, como consecuencia de una estructura de duplicidad, Derrida destruye la materialidad de la carta y propone su partición, convirtiendo este proceso en «l'un des plus puissants instruments de formalisation pour ce qu'on appelle "la déconstruction"» (1996a: 48). Si Dupin, en posición de analista, lo que hace es «rectifier, redresser, remettre dans le droit chemin ce qui est en souffrance» (1980a: 483), la intención de Derrida es señalar que cada carta, a su vez, deja siempre tras de sí otra carta, en el lugar donde se ha realizado la substitución. Ese juego reiterativo conlleva la reduplicación continuada de «lo mismo», haciendo que el proceso se extienda de manera interminable al infinito. Así, a través de la noción de divisibilidad, Derrida impide la detención de la carta y, como consecuencia, el momento dogmático que acompaña su estabilización que, como dice Major, «introduit donc dans le regard du détenteur soit un effet de leurre soit une tache aveugle» (2001: 59). Para Derrida, la carta sufre una partición y no siempre llega a su destino. No hay, entonces, presencia (ousia) sin diferencia; no existe la palabra plena, sólo la aporía del pharmakon: ese suplemento, esa figura de lo indecible que, desde la polisemia (y no tanto la contradicción, que sigue anclada en el sistema dialéctico), se desata de la presencia plena de la palabra heideggeriana que sustenta todo el sistema falo/logo-céntrico. La intención de Derrida (1972a) es deconstruir la confianza ciega que el psicoanálisis deposita en la metafísica de la presencia, el imperialismo del significante y la tiranía del orden simbólico ${ }^{6}$, a través del exceso an-

\footnotetext{
${ }^{5}$ La exclusión de la figura del narrador, dice Major, posibilita la construcción de una estructura triangular en el cuento de Poe (y en la interpretación de Lacan), que acaba por omitir el hecho de que el Ministro D también es la figura doble del narrador.

${ }^{6}$ Después de De la grammatologie (1967), Lacan tiene en cuenta las críticas que le dirige Derrida y su influencia quedará plasmada en los seminarios de Encore (1972-1973), llegando a modificar el dogmatismo de la teoría de la materialidad
} 
económico del motivo lítico que es el que posibilita la transgresión del orden simbólico, en la pérdida irreparable de la presencia.

Ahora, a través del proceso de la diseminación que da la bienvenida al vacío que le falta al sistema falo/logo-céntrico, Derrida se distancia de la metafísica de la presencia y recupera la escritura, que «vise toujours à retrouver le plaisir où la présence différée par calcul» (1968: 54). Desde el proceso de la diseminación o del espaciamiento como diferencia -que posibilita el encuentro con la violencia del goce an-económico-, Derrida deshace el orden simbólico del lenguaje, con el fin de destruir la omnipotencia del significante lacaniano. De esta manera, con el trazado estratégico de la diferencia, Derrida destruye la autorreferencialidad de la lógica falo-logo/céntrica, que se abre a la exterioridad que excede el sistema. Más allá del signo -como representación de una presencia plena-, Derrida introduce la mediación temporal que suspende el cumplimiento teleológico del ser-presente (la identidad) y, a través del proceso deconstructivo de la escritura, cuestiona el valor del origen y la clausura definitiva del análisis. Para Derrida, el signo es una presencia diferida, que no puede conducir a la presencia autoconsciente de un significado, en donde se estabilizaría el movimiento incansable de la significación; inscrito en una cadena de reenvíos infinita, por un juego sistemático de diferencias que lo alejan de sí mismo, el signo derridiano extiende el dolor y el sufrimiento, porque no puede cerrar el proceso analítico. Por eso, para Derrida (2000), la «lettre volée» siempre será una «lettre en souffrance»: es el dolor infinito que produce la destinerrancia de una ficción interminable, que queda suspendida en el vacío; es una crueldad reiterativa que, al igual que para Artaud, no tiene que ver con el dolor de la sangre (cruor, crudus, crudecitas), sino con una crueldad física «qui jouerait à jouir de souffrir d'un faire-souffrir ou d'un se faire-souffrir pour le plaisir» (2000: 12). Con el proceso de la deconstrucción, Derrida no trata de sublimar el dolor, sino que busca extender el sufrimiento, en el proceso interminable del análisis. Así, la deconstrucción como construcción de un «imposible» siempre «por-venir»- abre la promesa de una mesianicidad $\left(\sin\right.$ mesianismo ${ }^{7}$ ) que hace referencia a la llegada del acontecimiento en tanto que alteridad irreductiblemente heterogénea, en donde construir un au-delà de l'au-delà: es decir, un au-delà de la

del significante, a través del concepto de «goce». Así es como Lacan va a empezar a hablar de la cura interminable, de ese real que no cesa de (no) escribirse: «Le nécessaire [...] est ce qui ne cesse pas, de quoi? - de s'écrire. [...] Ce qui ne cesse pas de ne pas s'écrire, c'est une catégorie modale qui n'est pas celle que vous auriez attendue pour s'opposer au nécessaire, qui aurait été plutôt le contingent. [...] le nécessaire est conjugué à l'impossible, et que ce ne cesse pas de ne pas s'écrire, c'en est l'articulation. Ce qui se produit, c'est la jouissance qu'il ne faudrait pas» (1972-1973: 76).

${ }^{7}$ Término acuñado por Derrida y que trata, especialmente, en Spectres de Marx: l'état de la dette, le travail du deuil et la nouvelle Internationale (1993) y en «Foi et savoir. Les deux sources de la "religion" aux limites de la simple raison » (1996). En «Foi et savoir. Les deux sources de la "religion" aux limites de la simple raison», concretamente, dice: «le messianique, ou la messianicité sans messianisme. Ce serait l'ouverture à l'avenir ou à la venue de l'autre comme avènement de la justice, mais sans horizon d'attente et sans préfiguration prophétique. [...] Le messianique s'expose à la surprise absolue et, même si c'est toujours sous la forme phénoménale de la paix ou de la justice, il doit, s'exposant aussi abstraitement, s'attendre (attendre sans s'attendre) au meilleur comme au pire, l'un n'allant jamais sans la possibilité ouverte de l'autre. Il s'agit là d'une "structure générale de l'expérience". Cette dimension messianique ne dépend d'aucun messianisme, elle ne suit aucune révélation déterminée, elle n'appartient en propre à aucune religion abrahamique (même si je dois ici continuer, "entre nous", pour d'essentielles raisons de langue et de lieu, de culture, de rhétorique provisoire et de stratégie historique dont je parlerai plus loin, à lui donner des noms marqués par les religions abrahamiques)» (27-28). 
crueldad que -sin posibilidad de estabilizarse, al quedar al margen del sistema oposicional de la dialéctica- obliga a vivir (en) el dolor y la pérdida.

\title{
La fuerza política de la muerte
}

\author{
Alguna vez \\ alguna vez tal vez \\ me iré sin quedarme \\ me iré como quien se va. \\ Alejandra Pizarnik, Poesía completa
}

En 1990, en Let us not forget - Psychoanalysis, Derrida preguntaba: «On voudrait nous faire oublier la psychanalyse. Oublierions-nous la psychanalyse?» (Major, 2001: II-III). Hoy en día, el psicoanálisis está siendo violentado por un discurso tecnicista, que convierte a los hombres en simples objetos, sin reconocer la culpa, la intimidad, la consciencia, el deseo o el inconsciente; experiencias, todas ellas, que marcan la fragmentación del sujeto y que la clínica contemporánea, amparada en la metafísica onto-teológica de la presencia, intenta erradicar de manera desesperada, a través del consuelo del fármaco. Vivimos en una sociedad que, paradójicamente, dice Roudinesco: «Plus elle s'enferme dans la logique narcissique, et plus elle fuit l'idée de subjectivité» (Roudinesco, 1999: 49). En la sociedad depresiva, el psicoanálisis ha perdido su fuerza de subversión y no parece adaptarse a un mundo que se refugia en la psicología clínica y encuentra consuelo en la farmacología, dejando que el psicoanálisis se convierta en un reducto exclusivo de psicoanálisis para psicoanalistas. Ahora, dice Roudinesco, parece que «Le silence est alors préférable au langage, source d'angoisse et de honte» (1999: 34-35). En estos momentos, tal y como ya apuntó Freud (1938), la palabra se sustituye por el fármaco, en busca de un silencio cómplice con las prácticas psicoterapéuticas, cuya única finalidad es erradicar el síntoma, sin atender al motivo que lo ocasiona. La industria farmacéutica moderna, a través de la venta de depresivos, modifica y normativiza el comportamiento de los pacientes: suprime sus síntomas, pero no consigue cambiar la condición de su estado mental y crea dependencia de los tratamientos. Así, Leader llega a la conclusión de que «el remedio puede funcionar como un espejo de la enfermedad» (2008: 9), haciendo que producir y erradicar el sufrimiento, para las industrias farmacológicas, sean uno y el mismo proceso.

En este contexto, cuando el psicoanálisis ha quedado desplazado por la centralidad de la psicofarmacología, Derrida plantea: «Faire de la psychanalyse sa propre contemporaine, une telle chose est-elle pensable?» (1981: 344). Para que el psicoanálisis vuelva a ser contemporáneo, explica Derrida, es necesario que abandone la ideología de la felicidad y que incite a repensar el motivo lítico; en ese juego del fort/da, el psicoanálisis debe acoger la no-propiedad de la pulsión de muerte, en donde emerge la crueldad y el dolor por una pérdida irremediable. Así, en una sociedad en donde, como dice Dufourmantelle, «Uno es desposeído de lo que justamente no le pertenece, porque ése es 
el lugar del mayor riesgo. Lo que uno no posee y lo que lo obsesiona» (1997: 104-105), el psicoanálisis tiene que dar cabida al movimiento lítico, para pensar una nueva forma de soberanía cercana a la de Bataille $(1957)^{8}$-, entendida como desposesión; la comicidad, entonces, como angustia que desestructura la metafísica de la propiedad, revelaría que la vida se protege con la muerte. Así, en un mundo de autómatas empastillados -en donde la seducción de las tecnologías se dedican a eliminar el sufrimiento-, el psicoanálisis tendría que incitar a repensar el momento aneconómico de la destrucción, ofreciendo su hospitalidad a la muerte. Sin alivio. De este modo, a través de la aceptación de ese mourir-de-sa-propre-mort ${ }^{9}$ se podría pensar una nueva soberanía como pérdida de lo propio- sin necesidad de recurrir a una reconstrucción irresponsable de la metafísica de la presencia, a través del engaño del fármaco. El discurso político, ético y jurídico, entonces, debería reintegrar el psicoanálisis, porque para Derrida es «Le seul discours qui puisse aujourd'hui revendiquer la chose de la cruauté psychique, comme son affaire propre» (2000: 12).

\section{¿Un nuevo psicoanálisis deconstruccionista?}

A pesar de las desavenencias, tanto la deconstrucción como el psicoanálisis están movidos por una pasión que deshace, de-sedimenta y reconstituye ideas, doctrinas, instituciones y posiciones dogmáticas. Ambos reflexionan sobre la imposibilidad del acto de decir(se) y, concretamente, sobre el punto ciego de la significación, como una herencia freudiana que reciben los dos y que los mantiene unidos en la discordia. Por eso, la finalidad de la deconstrucción derridiana no es desacreditar la ciencia psicoanalítica, sino repolitizar su pensamiento, con el fin de que pueda volver a enfrentarse con el dolor y la seriedad del mundo contemporáneo.

En 1990, en el coloquio Lacan avec les philosophes, René Major se presenta con una ponencia titulada: «Depuis Lacan: y a-t-il une psychanalyse “derridienne”?». El título es censurado por Alain Badiou y queda del siguiente modo: «Depuis Lacan: - », con un guión que pretende sustituir lo censurado, pero que deja la huella de la prohibición visible y bien impresa. Evidentemente, el motivo de la censura se debe a que Major, en estos momentos, está planteando la posibilidad de un nuevo psicoanálisis, a partir de la deconstrucción derridiana: un psicoanálisis que, más allá de la preocupación arqueológica por el origen y la palabra plena, tiende a la mortificación del motivo lítico -como un proceso perturbador e inquietante- que desarticula el hermetismo y la autocomplacencia del archivo, extendiendo el análisis al infinito. Al fin y al cabo, para Derrida, el motivo lítico demuestra que hay una resistencia del psicoanálisis con respecto a sí mismo: una autotanatografía que lo ex-propia más allá de sus propios límites internos, poniéndolo en contacto con ese mourir-de-

\footnotetext{
${ }^{8}$ El ser, según explica Bataille, es paradójico: si no se comunica se aniquila, pero si se abre al contacto con el «otro», se arriesga igualmente a perderse a sí mismo. En el erotismo, cuando el sujeto entra en contacto con el «otro», el ser sale fuera de sí mismo y el sujeto deja de ser. El acceso a la intimidad se consigue, entonces, a través de la exteriorización del ser en la comunicación. El sujeto es soberano en la medida en que ya no es; la soberanía del sujeto está en el exceso que lo conduce a su propia extinción: la ausencia del ser, la pérdida, es su soberanía. La ontología de Bataille, su interés por el ser, se convierte en una (no)ontología, en donde el sujeto es, paradójicamente, en tanto que no es (véase Bataille, 1957).

${ }^{9}$ Terminología empleada en «Spéculer-Sur Freud» (Derrida, 1980b: 419).
} 
sa-propre-mort que lo desintegra poco a poco. Y, tal y como piensa Derrida, el psicoanálisis debe reflexionar -sin ningún alivio teológico o humanista- sobre ese más-allá de la economía que abre la pulsión de muerte, como (no)lugar de un sufrimiento interminable que dinamita la posibilidad de la palabra plena en el análisis. Ahí, desde la irreverencia de un gesto que acerca precisamente lo que nunca se posee, el psicoanálisis podrá volver a replantear un discurso, claramente político y provocador, sobre el sufrimiento y la crueldad en el mundo contemporáneo. En esa amistad que afirma, pero también deconstruye, se encuentra la posibilidad de repolitizar y salvar el psicoanálisis: el «quizá» de un «por-venir» que siempre está por hacerse, en una relación de amistad -sincera y comprometida- entre el psicoanálisis y la deconstrucción.

\section{Referencias bibliográficas}

Althusser, L. - Balibar, É. - Establet, É. - MACherey, P. - RAncière, J. (1965): Lire le capital. París, Quadrige, 1996.

Bataille, G. (1957): El Erotismo. Barcelona, Tusquets Editores, 2007.

Deleuze, G. - Guattari, F. (1972): El Anti-Edipo. Capitalismo y esquizofrenia. Barcelona, Ediciones Paidós Ibérica, 1985.

DERRIDA, J. (1967a): De la grammatologie. París, Éditions de Minuit. (1967b): «Freud et la scène de l'écriture», en L'Écriture et la différence. París, Éditions du Seuil, 2006, p. 293-341.

(1968): «La différance», en Marges de la Philosophie. París, Éditions du Seuil, 1972, pp. 129.

(1972a): La dissémination. París, Éditions du Seuil, 2006.

(1972b): Positions, París: Les Éditions de Minuit.

(1980a): «Le facteur de la vérité», en La carte postale: de Socrate à Freud et au-delà. París, Flammarion, pp. 439-524.

— (1980b): «Spéculer - Sur "Freud”», en La carte postale: de Socrate à Freud et au-delà. París, Flammarion, pp. 275-437.

- (1981) «Geopsychanalyse "and the rest of the world"», en (1987), Psyché, inventions de l'autre. París, Galilée, 1998, pp. 327-353.

- (1993): Spectres de Marx: l'état de la dette, le travail du deuil et la nouvelle Internationale. París, Éditions Galilée.

— (1994): Politiques de l'amitié. París, Éditions Galilée, 2003.

_ (1995): Mal d'archive: une impression freudienne. París, Éditions Galilée.

- (1996a): Résistances de la psychanalyse. París, Éditions Galilée.

(1996b): «Foi et savoir. Les deux sources de la "religion" aux limites de la simple raison», en

J. DerridA, Jacques y G. VATtimo, eds., La religion. París, Éditions du Seuil, 1996.

- (2000): États d'âme de la psychanalyse. Adresse aux États Généraux de la Psychanalyse. París, Éditions Galilée. 
Derrida, J. - Dufourmantelle, A. (1997): La hospitalidad. Buenos Aires, Ediciones de la Flor, 2000.

Derrida, J. - Roudinesco, É (2001): De quoi demain... Dialogue. París, Librairie Arthème Fayard et Éditions Galilée.

Dosse, F. (1992): Historia del estructuralismo. Tomo I: el campo del signo 1945-1966 y Tomo II: el canto del cisne, 1967 hasta nuestros días. Barcelona, Ediciones Akal, 2004.

FREUD, S. (1900): «La interpretación de los sueños», en Obras Completas IV: La interpretación de los sueños. Buenos Aires, Amorrortu Editores, 1979, pp. 1-613.

- (1916-1917): «Los caminos de la formación del síntoma», en Obras Completas XVI: Conferencias de introducción al psicoanálisis (Parte III) (1916-1917). Buenos Aires, Amorrortu Editores, 1978, pp. 326-344.

(1937): «Análisis terminable e interminable», en Obras Completas XXIII: Moises y la religión monoteísta, esquema de psicoanálisis y otras obras. Buenos Aires, Amorrortu Editores, 1986, pp. 211-255.

- (1938): «Esquema del psicoanálisis», en Obras Completas XXIII: Moises y la religión monoteísta, esquema de psicoanálisis y otras obras. Buenos Aires, Amorrortu Editores, 1986, pp. 133-211

LACAN, J. (pronunciado 1955; publicado 1956): «Le Séminaire sur La Lettre volée», en Écrits. París, Éditions du Seuil, 1966, pp. 11-61.

- (1972-1973): Encore. París, Éditions du Seuil, 1999.

LEADER, D. (2008): La moda negra: duelo, melancolía y depresión. Madrid, Editorial Sexto Piso, 2011.

MAJOR, R. (2001): Lacan avec Derrida. París, Flammarion.

- (2007): Derrida pour les temps à venir. París, Éditions Stock.

RoudinesCo, É. (1999): Pourquoi la psychanalyse? París, Champs Essais, 2009. 